\title{
Seasonal changes of sea-ice characteristics off East Antarctica
}

\author{
IAN ALLison AND ANTHONy Worby \\ Antartic Cooperative Research Centre, Box 252C, Hobart, Tasmania 7001. Australia and Austratian Antarctic Division
}

\begin{abstract}
Data on Antarctic sea-ice characteristics, and their spatial and temporal variability, are presented from cruises between 1986 and 1993 for the region spanning $60^{\circ}-150^{\circ} \mathrm{F}$ between October and May. In spring, the sea-ice zone is a variable mixture of different thicknesses of ice plus open water and in some regions only $30-40 \%$ of the arca is covered with ice $>0.3 \mathrm{~m}$ thick. The thin-ice and openwater arcas arc important for air-sca hcat cxchange. Crystallographic analyses of icc cores, supported by salinity and stable-isotope measurements, show that approximately $50 \%$ of the ice mass is composed of small frazil crystals. These are formed by rapid ice growth in leads and polynyas and indicate the presence of open water throughout the growth scason. 'The area-averaged thickness of undeformed ice west of $120^{\circ} \mathrm{E}$ is typically less than $0.5 \mathrm{~m}$ and tends to increase with distance south of the ice edge. Ice growth by congelation freezing rarely exceeds $0.4 \mathrm{~m}$, with increascs in ice thickness beyond this mostly attributable to rafting and ridging. While most of the total area is thin ice or open water, in the central pack much of the total ice mass is contained in ridges. Taking account of the extent of ridging, the total area-averaged ice thickness is estimated to be about $1 \mathrm{~m}$ for the region $60^{\circ}-90^{\circ} \mathrm{E}$ and $2 \mathrm{~m}$ for the region $120^{\circ}-150^{\circ} \mathrm{E}$. By December, new ice formation has ceased in all areas of the pack and only floes $>0.3 \mathrm{~m}$ remain. In most regions these melt completely over the summer and the new season's ice formation starts in late February. By March, the thin ice has reached a thickness of $0.150 .30 \mathrm{~m}$, with nilas formation being an important mechanism for ice growth within the ice edge
\end{abstract}

\section{INTRODUCTION}

The thickness distribution of sea ice within the Antarctic pack is fundamentally important to the interaction between Antarctic sea ice, the atmosphere and the ocean, and is determined by a combination of dynamic and thermodynamic processes. Observations have shown that during most scasons in the Antarctic a complicated and highly variable mixture of open water and different types and thicknesses of ice are present. Some recent studies indicate that the typical thickness of undeformed Antarctic floes is only $0.3-0.5 \mathrm{~m}$ both in the Weddell Sea (Wadhams and others, 1987) and East Antarctica (Allison, 1989a; Allison and others, 1993). Undeformed ice is defined as that which may have been rafted to form thicker uniform floes but has not becn ridged; this definition has been adopted because in most cases shipbased observations cannot distinguish flocs which have been uniformly rafted. In spring, up to $25 \%$ of the pack around East Antarctica has been estimated to consist of thin sea icc less than $0.3 \mathrm{~m}$ thick, with a further $30 \%$ being open water (Allison and others, 1993). These thinice and open-water areas are important as regions of very high air-sca heat exchange and rapid new ice formation (Maykut, 1978; Worby and Allison, 1991). In deformed areas, however, ice thickness can exceed $5 \mathrm{~m}$ and much of the total ice mass is contained within pressure ridges.

\section{OBSERVATIONAL DATA SET}

In this paper, ship-based observations are used to estimate and describe seasonal and regional changes in ice characteristics and thickness distribution between $60^{\circ}$ and $150^{\circ} \mathrm{E}$. The data consist of approximately 1500 observations from 17 voyages between October 1986 and May 1993. Each hourly observation made from the ship is an estimate of the areal coverage, snow cover, topography and floe size of the three dominant ice-thickness categories within a radius of $1 \mathrm{~km}$ from the vessel. The ice-thickness categories are those defined by the WMO nomenclature (World Meteorological Organization, 1970) and the. obscrvations are similar to those described by Allison and others (1993), although the observational technique has been updated several times to include additional detail. Since 1992, for example, the observations include an estimate of the areal coverage and average sail height of pressure ridges which is used to estimate the average thickness of ridged floes. This contrasts with observations prior to 1992 which are predominantly of undeformed ice.

The accuracy of thickness observations made from the ship is within about $20 \%$ of total thickness, but the large sample of obscrvations can be expected to provide a good statistical description of the pack characteristics. At least one of the authors was present on the majority of voyages and, at the start of each cruise, all observers would 
observe simultaneously to minimize differences duc to individual judgment. Snow-free thin-ice categories, which are particularly important for heat exchange, can be reliably classified by a traincd observer into the correct WMO category from their apparent albedo. For older, snow-covered floes, ice thickness was visually estimated from broken pieces turned on their side by the passage of the ship (using as a reference scale a spherical buoy suspended over the vessel's side close to the water line), or for very thick floes, from the freeboard. On dedicated scientific cruises, regular in-situ measurements of ice and snow thickness were also made by drilling: these measurements were used to check and "calibrate" the ship-based observations. The ship-based obscrvations of ridge sail height are subject to considerably greater error than the ice thickness, particularly under overcast conditions.

Each voyage was in the pack ice for between $3 \mathrm{~d}$ and 3 weeks, and was either a resupply voyage to one or more Antarctic bases or a dedicated scientific voyage. The dedicated voyages include sections following specified direct cruise tracks (regardless of ice conditions), generally running north-south between the ice edge and the continent, whilst the resupply voyages are reliable for visiting roughly the same area at the same time each ycar. Typical cruise tracks are shown in Figure 1. The data set has been edited to exclude observations biased by slow progress in heavy icc and by open water when transiting near the ice edge. When aircraft were on board, flights were made as frequently as possible to observe sea-ice conditions and check that ship-based observations were not biased by easily navigable routes. The differences in mean ice-thickness estimates between sections along specified tracks and resupply routes were no greater than the differences between individual specified tracks, suggesting that the obser-vations on resupply voyages are not significantly biased towards lighter ice conditions.

Core sampling of ice floes has been undertaken on voyages since 1991. Stratigraphic analyses of sections from 53 cores have been used to determine the crystal structure and growth processes of sea-ice floes, including any deformation that may have occurred, and the relative percentages of frazil and congclation icc. Salinity and stable-isotope $\left(\delta^{18} \mathrm{O}\right)$ analyses typically at $0.03 \mathrm{~m}$ vertical intervals) have been used to determine the presence of snow icc.

\section{DATA ANALYSIS}

To examine regional and seasonal differences in ice conditions, we have divided the data into three scctors: sector I $\left(60^{\circ}-90^{\circ} \mathrm{E}\right)$, sector II $\left(90^{\circ} 120^{\circ} \mathrm{E}\right)$ and sector III

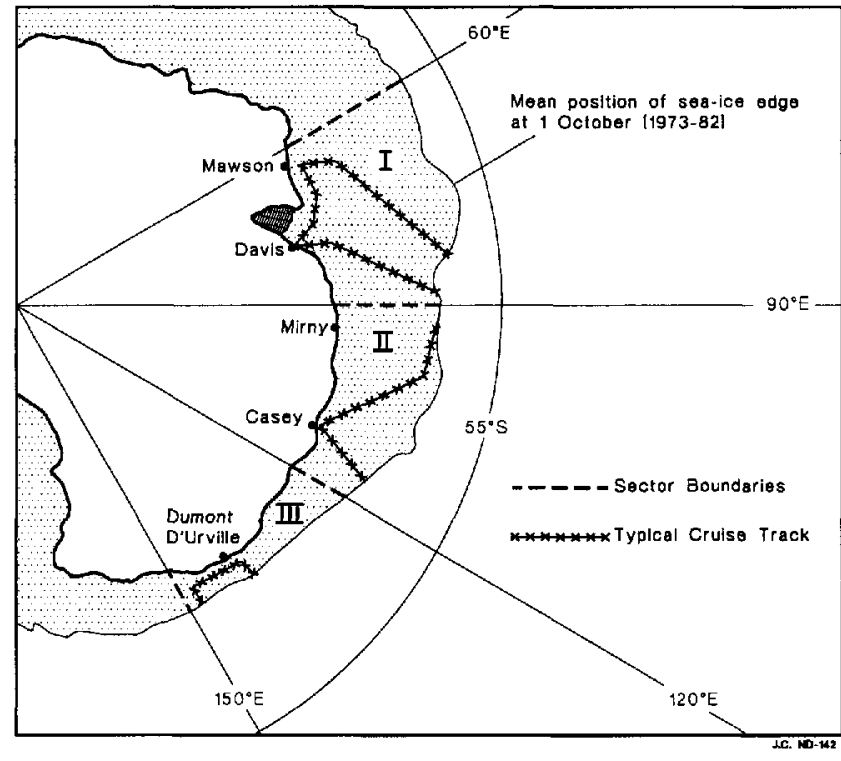

Fig. 1. East Antarctica showing the regional divisions (sectors I-III) used in this study and typical cruise tracks on which sea-ice ubservations are available. The mean position of the sea-ice edge is shown for 1 October (U.S. Naval Oceanography Command, 1985).

$\left(120^{\circ}-150^{\circ} \mathrm{E}\right)$, and further subdivided these sectors into five zones between the ice edge (defined by the NOAA Joint Ice Centre weekly ice charts at $15 \%$ concentration) and the Antarctic continent. These zones are $0-50 \mathrm{~km}$, $50-150 \mathrm{~km}, 150-350 \mathrm{~km}, 350-550 \mathrm{~km}$ and $>550 \mathrm{~km}$ from the ice edge. We have also simplificd the ship-based observations into four undeformed ice-thickness categories based on important phases in the ice-growth cycle (Worby and Allison, 1991). The four categories are open water, $0-0.15 \mathrm{~m}, 0.15-0.3 \mathrm{~m}$ and $>0.3 \mathrm{~m}$. The fractional coverage of these catcgories is shown in Figure 2 as well as the area-averaged ice thickness, calculated over the total area of the pack (including open water), but excluding the effects of deformation. Dedicated scientific voyages are marked by an asterisk in Figure 2.

\section{SEASONAL GHANGES IN UNDEFORMED ICE THICKNESS}

\subsection{Late spring}

The majority of the data are from sectors I and II during latc spring (Octobcr-November) when there is a broad mix of the four thickness categories, reflecting the

Table 1. Average percentage of frazil crystals, congelation ice and snow ice for cores from late spring sea-ice in sector $I$

Voyage No. of cores

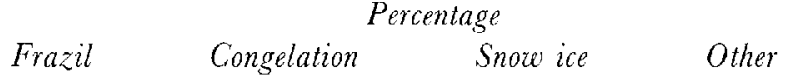

8-19 Nov 1991

25 Oct-15 Nov 1992
8

19
46

48
38

34
12

12
4

6 


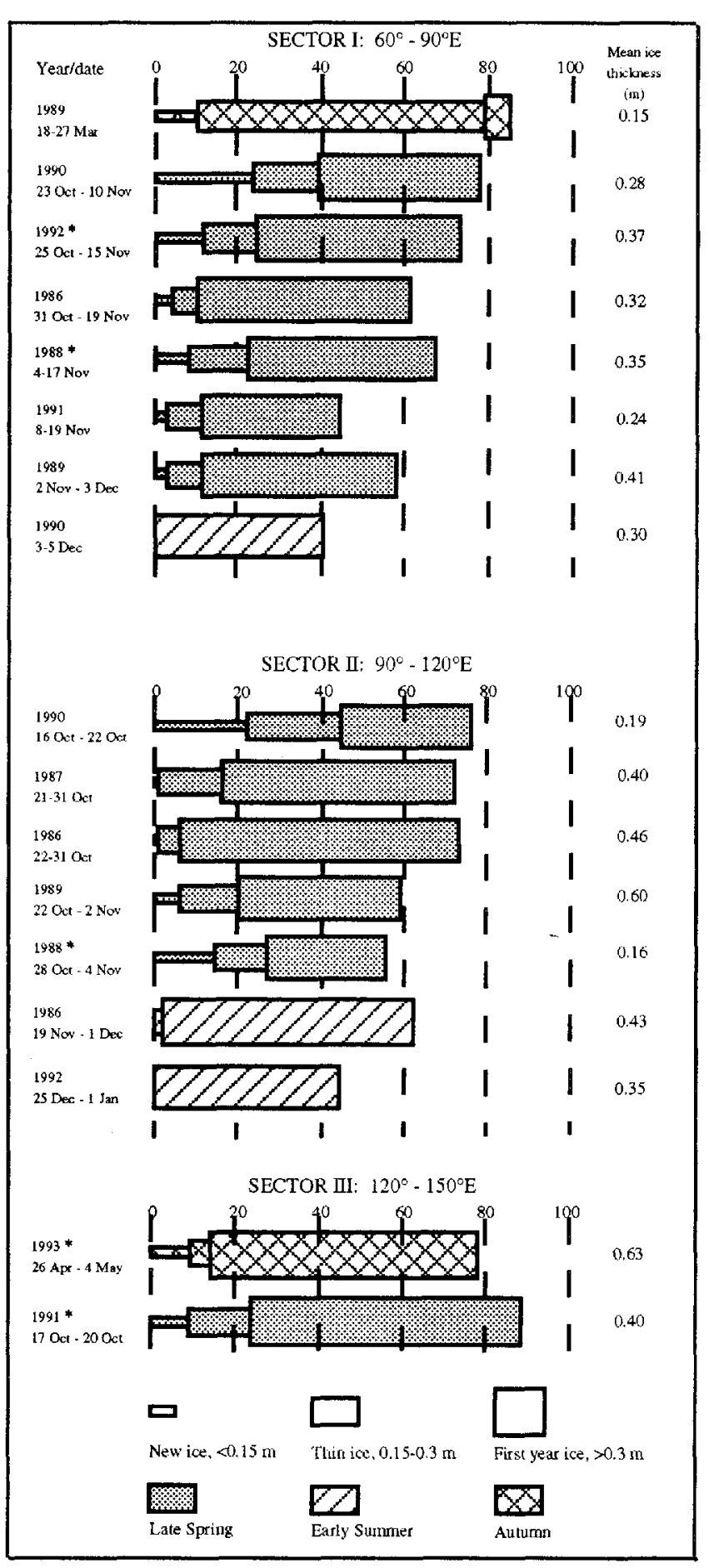

Fig. 2. Percentage concentration of three ice-thickness and open-ixater categories for each voyage. The relative concentrations of the different categories are shown separately for each regional sector and the voyages are classified by season. The area-averaged undeformed ice thickness for each voyage is shown at the right. Dedicated scientific cruises are denoted by an asterisk.

variation in ice thickness within the pack. At this time of year, open water and ice $>0.3 \mathrm{~m}$ thick are dominant and account for $60-90 \%$ of the total pack. The thinner ice categories are present in lower and more variable concentrations $(10-40 \%)$ and large areas of nilas or pancake ice are common in newly formed leads. Crystaltexture analysis of cores has shown that approximately $50 \%$ of pack ice is composed of frazil crystals, indicative of rapid new-ice formation in open water with subsequent thickness increases caused by deformation. Table 1 shows the percentage of different ice types for cores taken from sector I. Structural analysis shows that much of the ice $>0.3 \mathrm{~m}$ thick has been rafted or ridged and the increases in ice thickness beyond $0.4-0.5 \mathrm{~m}$ are usually the result of these dynamic processes. This is exemplified by the typical core profiles shown in Figure 3. Rafted floes can usually be identified by repeated layers of frazil and congelation crystals or by multiple "c-curves" in the salinity profile. The $\delta^{18} \mathrm{O}$ profiles are used to discriminate ice which forms when snow becomes saturated with sea water and refreezes (Lange and others, 1990). Visual identification of this ice type is difficult because of its similarity to coarse-grained frazil crystals but its meteoric water component results in a more negative $\delta^{18} \mathrm{O}$ value than standard sea ice. In the samples analysed, approximately $12 \%$ of the ice cover was composed of this snow icc, which was usually found at the top of cores but also at depth in rafted floes.

During October-November, $40-50 \%$ of the pack in sector $\mathrm{I}$ is composed of ice $>0.3 \mathrm{~m}$ and this shows little inter-annual variation except in 1991. The inter-annual changes in total ice concentration during this period therefore reflect changes in the relative percentages of new ice and open water, and this is determined largely by air temperatures becoming warm enough to prevent newice growth. This typically occurs around mid-November but there are latitudinal and annual fluctuations. Interannual changes in the mean undeformed spring ice thickness in sector $\mathrm{I}$ range between 0.24 and $0.41 \mathrm{~m}$. These somewhat low values reflect the high percentage of open water within the pack at this time of year. The concentration of new ice, and hence the total ice concentration, decreases though October and November as air temperatures rise and leads fail to refreeze.

In sector II, there are fewer data and the thickness distribution shows greater annual variability with the area-averaged undeformed ice thickness ranging between 0.16 and $0.60 \mathrm{~m}$. In sector III, local influences on pack-ice drift result in heavy conditions most of the year and the ice is significantly thicker than in sectors $I$ and II. Grounded iceberg tongues near $150^{\circ}$ and $136^{\circ} \mathrm{E}$, and the remnants of the gigantic $\mathrm{B} 9$ iccberg from the Ross Ice Shelf, form barriers to the westward flow of sea ice, causing ice to build up on their windward sides. The subsequent ridging which occurs can result in floes in excess of $10 \mathrm{~m}$ thick with a snow cover of $1-2 \mathrm{~m}$. Near the ice edge, vast pancake-ice fields have been observed. during late spring but hcavy ice in the $50-150 \mathrm{~km}$ zone has prevented observations further south.

4.1.1. Latitudinal variations in ice conditions in seclors $I$ and $I I$ The area-averaged undeformed ice thickness in OctoberNovember for sectors I and II, and its variability, is shown as a function of distance from the ice edge in Figure 4 . The change in mean undeformed ice and snow thickness with distance from the ice edge is remarkably constant from year to year in sector I but there are significant annual variations in sector II where the iceedge location is more variable.

In the two outer zones $(0-150 \mathrm{~km})$, ice concentration is typically only $20-30 \%$ and the area-averaged ice 


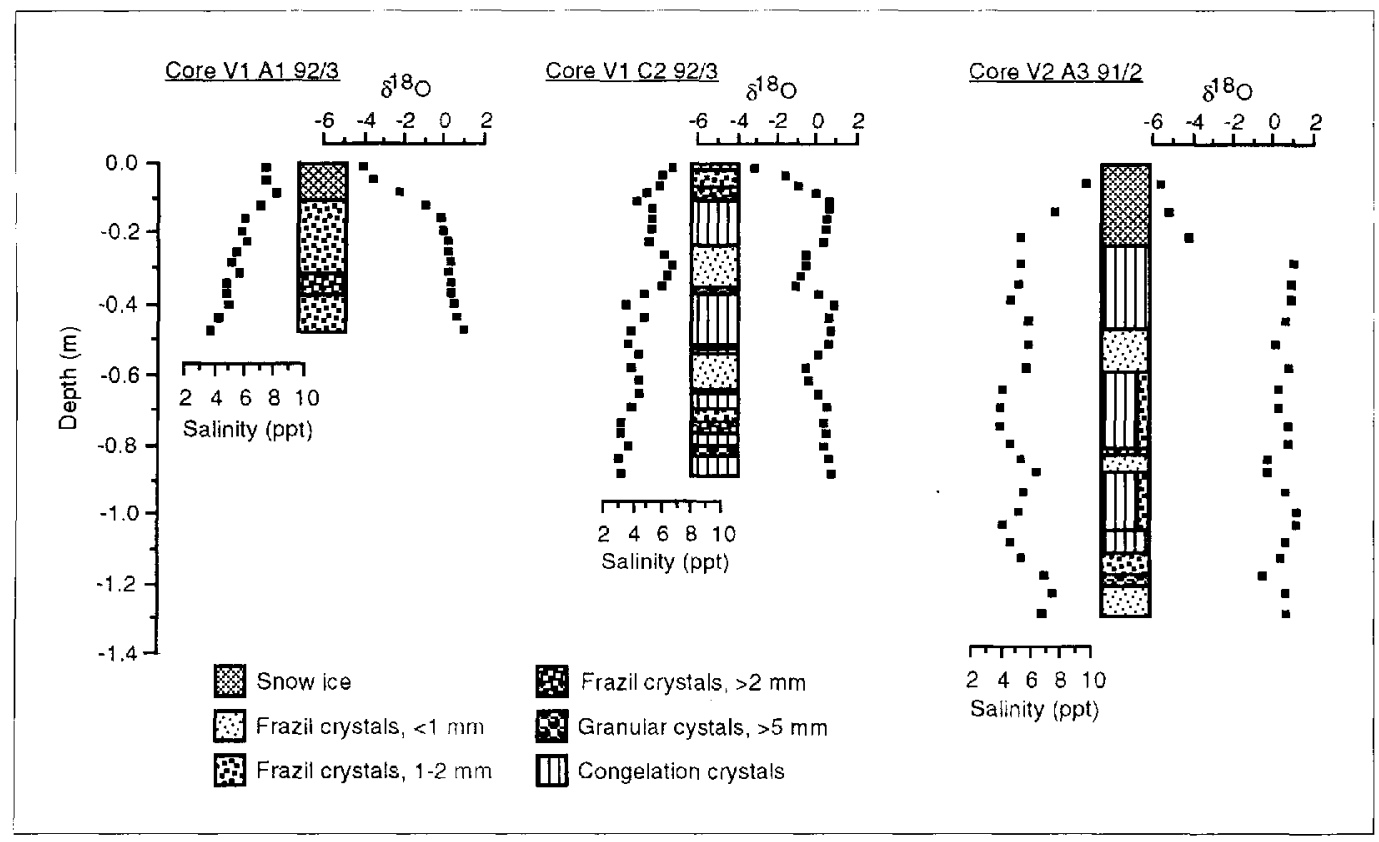

Fig. 3. Profiles of crystal structure, salinity and $\delta^{18}$ O for three typical cores collected from late-spring pack ice in sector $I$.

thickness is heavily weighted by the high percentage of open water. The ice-covered region in both zones is usually composed of small floes $0.5-2.0 \mathrm{~m}$ thick with new ice forming only in the vicinity of thicker floes due to localized cooling.

In the $150-350 \mathrm{~km}$ and $350550 \mathrm{~km}$ zones, there is an increase in ice concentration, mostly in the $>0.3 \mathrm{~m}$

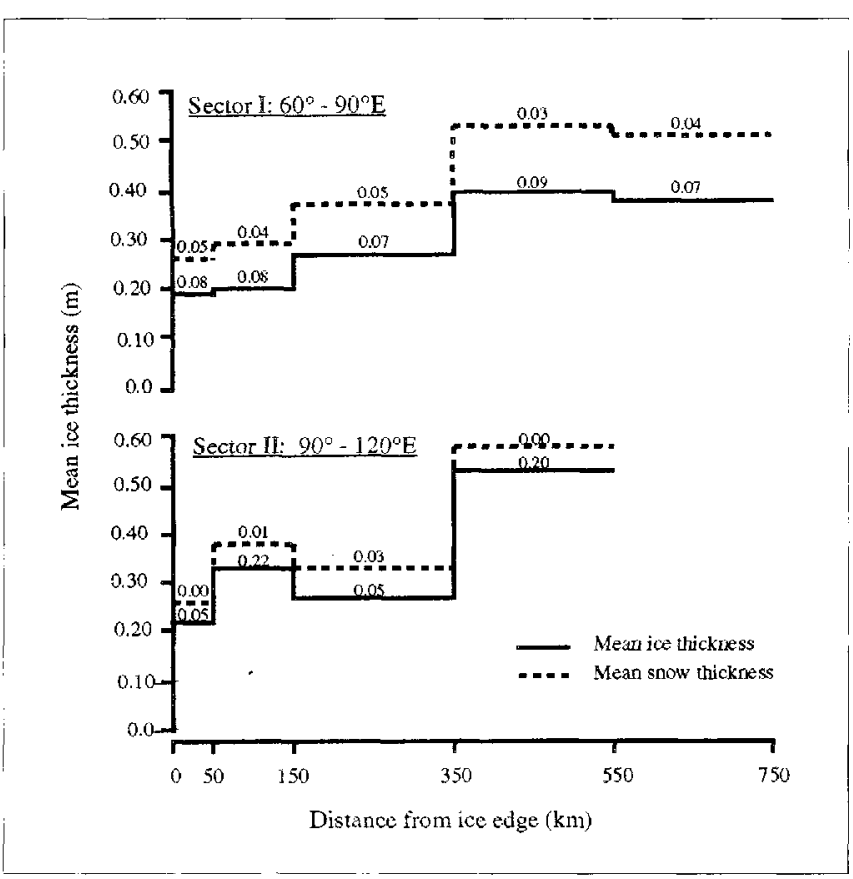

Fig. 4. Changes in the undeformed area-averaged ice thickness and snow thickness with distance from the ice edge for October-November. Snow thickness is shown as a cumulative addition to the ice thickness. Numbers on the graph represent one standard deviation of the means for different voyages; averages and deviations are based on data from six voyages in sector $I$ (1986-92) and six voyages in sector $I I(1986-90)$. category. The concentration of new ice also increases and large areas of nilas are common in leads up to several kilomctres across. This ice quickly thickens or is crushed into ridges by thicker converging floes. The mean undeformed thickness in sector II is more variable but comparable with scctor I, and the trend toward thicker ice south of the ice edge is clear in both sectors.

In sector $I$, there is a decrease in the area-averaged undeformed ice thickness in the $>550 \mathrm{~km}$ zone where as much as $60 \%$ of the pack is composed of open water and ice $<0.3 \mathrm{~m}$ thick. This is due to a rccurrent flaw lead between the fast ice and the pack and the northward advection of new ice away from this area. There are insufficient data to comment on this zone in sector 11 .

The average snow-cover thickness as a function of distance from the icc cdge is also shown in Figure 4 . The inter-annual variability in the snow cover in sector $I$ is low and there is a small but uniform increase in average snow thickness from $0.07 \mathrm{~m}$ near the ice edge to $0.13 \mathrm{~m}$ in the $350-550 \mathrm{~km}$ zone. In sector II, there is less snow cover with no significant increase south of the ice edge. The snowthickness values are averaged over the ice-covered area only.

\subsection{Early summer}

By Dccmber, new-ice formation has ceased and the thin ice present during November has either melted or been deformed into thicker floes. Most of the ice in sectors I and II consists of floes about $0.7 \mathrm{~m}$ thick with an areaaveraged value between 0.3 and $0.4 \mathrm{~m}$. Whilst this is comparable with the value for late spring, the ice edge is considerably further south and there has been a net loss of ice.

\subsection{Autumn}

Very little ice survives the summer melt in sector I and by late March the pack consists almost entirely of young ice. 'The majority of this is $<0.3 \mathrm{~m}$ thick with a high concentration $(80 \%)$ which is attributable to the rapid production of ice. 
In sector III, a high proportion of the ice trapped near iceberg tongues along the coast survives the summer melt, drifting north whenever the build-up of ice is too much to contain. Consequently, the ice-edge zone in autumn contains a high percentage of ice $2.05 .0 \mathrm{~m}$ thick, as well as occasional floes up to $10 \mathrm{~m}$ thick. Crystallographic analysis of the top $3 \mathrm{~m}$ of one $10 \mathrm{~m}$ thick floe revealed $100 \%$ frazil crystals, suggesting that it formed by continuous deformation of thinner floes. The $2 \mathrm{~m}$ thick snow cover showed multiple mclt layers, indicative of ice that has survived at least one summer season. During autumn 1993, heavy ice prevented the ship from penetrating beyond the $50-150 \mathrm{~km}$ zonc but aerial reconnaissance showed vast areas of nilas $0.05-0.15 \mathrm{~m}$ thick covering hundreds of square kilometres further south. Because this area was not included in our hourly ship-based observations, the area-averaged thickness calculated for this sector is biased by the heavy ice in the $0-150 \mathrm{~km}$ zones.

\section{CONTRIBUTION OF RIDGING TO TOTAL SEA- ICE MASS}

Buoy studies have shown that the pack ice off East Antarctica is highly dynamic. Drift rates of $15-20 \mathrm{~km} \mathrm{~d}^{-1}$ are typical (Allison, 1989b) and much higher rates are not uncommon. Such dynamism often results in the deformation of ice soon after it has formed, e.g. fingerrafting of nilas and stacking of small pancakes as well as rafting and ridging of thicker first-year flocs. Analysis of pack-ice floes shows that deformation, rather than basal freezing, is the dominant mechanism for increasing ice thickness beyond $0.20 .4 \mathrm{~m}$. This results in an increase in local ice thickness, whilst at the same time leads open and, during the growth scason, new ice is able to form. The net effect is increased ice production, resulting in an increase in the total mass of ice within the pack and changes in the ice-thickness distribution. There is also an increase in brine rejection to the ocean during the growth season and fresh-water flux during the melt.

The initial deformation of thin ice creates relatively uniform thicker ice that is included in our observations, but the effect of ridges is not included in any of the estimates of ice thickness given in the previous sections. The accurate assessment of the thickncss of ice in heavily ridged floes is impossible from a ship because the bulk of the ice mass is below the water line. We have therefore attempted to relate the average icc thickness of a ridged floc to visible features: the areal extent of ridging on the surface, the average sail height and the undeformed thickness of the floc.

Using a simple model of a ridge with a triangular sail cross-section of average height $S$, in ice of undeformed thickness $z_{11}$, the average ice thickness above freeboard, $z_{\mathrm{f}}$, is given by:

$$
z_{\mathrm{f}}=\left(0.5 R S+0.1 z_{11}\right)
$$

where $R$ is the fraction of surface area ridged. Assuming hydrostatic equilibrium and an ice density of $900 \mathrm{~kg} \mathrm{~m}^{-3}$, the total average thickness, $z_{\mathrm{r}}$, of the ridged floc is then simply:

$$
z_{\mathrm{r}}=10 z_{\mathrm{f}}
$$

Nine ridge-thickness profiles from floes in sectors I and III are shown in Figure 5. These profiles were obtained by drilling regularly spaced holes across the ridge and measuring the total ice and snow thickness and freeboard height at each hole. Also shown in Figure 5 for each profile is the average ice thickness from the profile measurements $\left(z_{a v}\right)$, the average ridge thickness $\left(z_{\mathrm{r}}\right)$ calculated from Equations (1) and (2), the ratio of $z_{\mathrm{ar}}$ to the thickness of undeformed ice in the floe $(\mathrm{R} l)$ and the ratio of the average thickness required for hydrostatic balance assuming an ice density of $900 \mathrm{~kg} \mathrm{~m}^{-3}$ and snow density of $400 \mathrm{~kg} \mathrm{~m}^{3}$ ) to the thickness of undeformed ice in the floe $(\mathrm{R} 2) . \mathrm{R} 1$ is the ratio of total mass in the floes compared to that in the thinner undeformed ice and, with the exception of ridge $\mathrm{H} \mathrm{I}$, it has a range between 1 and 3 . Ridge $\mathrm{H} \mathrm{I}$ $(\mathrm{R} 1=6.5)$ is an example of a relatively thin floe ridging against a thicker floe, and hence the undeformed ice thickness used in the calculation is not representative of both floes. Although the measured profiles may represent only a small section of each floe, the good agreement between R1 and R2 shows that the average thickness calculated from the measured profile is close to the hydrostatic average in all cases. The average ice thickness calculated as $z_{\mathrm{r}}$ is close to $z_{\mathrm{a}}$ and, considering the simplicity of formulation, Equations (1) and (2) provide a reasonable thickness correction for ridging.

Fquations (1) and (2) have therefore been used to derive an arca-averaged ice thickness which includes the effect of ridging from ship-based estimates of the ridging fraction and sail height for each of the three dominant ice categorics around the vessel. This is a more accurate indication of the total mass of ice and hence the total ice production within the Antarctic pack. T'able 2 compares the area-averaged ice-thickness calculations for undeformed and ridged ice for voyages in sector I (October 1992) and sector III (May 1993). The ratio of deformed to undeformed ice thickness for the total pack is about 3 , in general agreement with the ratios for the nine measured ridge profiles on the same voyages.

In sector I, ridging steadily increases from near zero in the zones closest to the ice edge to a maximum near the coast. This effectively increases the corrected average ice thickness by a factor from 1 to nearly 4 over the undeformed estimates shown in Figure 4. The ridgingcorrected estimate of an average pack-ice thickness of $1.6 \mathrm{~m}$ near the coast (Table 2) compares with a typical maximum fast-ice thickness at Mawson, where the ice growth is purely thermodynamic, of between 1.5 and $1.7 \mathrm{~m}$ (unpublished data of $\mathrm{I}$. Allison). The total avcragc thickness, corrected for ridging, for all of sector I is about $1 \mathrm{~m}$. In sector III, however, there is considerable ridging even in the zone closest to the ice edge and the corrected average thickness for the whole sector is around $2 \mathrm{~m}$. No data are available for sector II.

\section{CONCLUSIONS}

The extremes of ice thickness found within the Antarctic pack are important for different reasons. Thin ice $(<0.3 \mathrm{~m})$ is crucial to the exchange of heat between the occan and atmosphere, and thick ice $(>1 \mathrm{~m})$ contains the bulk of the ice mass within the pack. In this paper, 


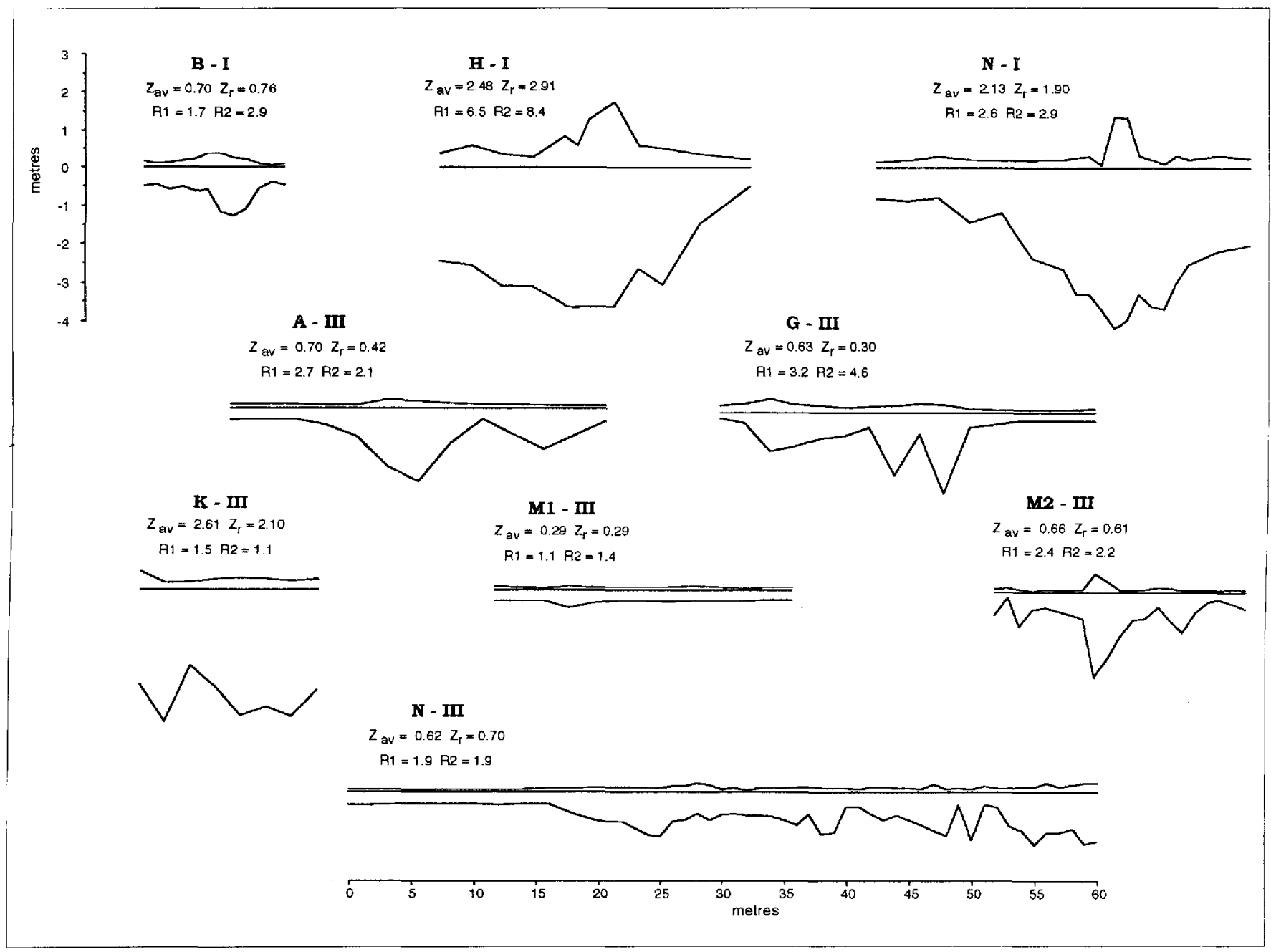

Fig. 5. Ridge-thickness profiles from floes in sectors $I$ and III during late spring. Refer to texl for details.

Table 2. Area-averaged ice thickness for zones of zarying distance from the ice edge. The average thickness calculated from observations of undeformed ice only is compared with the average thickness estimated with account of ridging. Observations are from lwo voyages: (i) 25 October-15 November 1992 (sector I) and (ii) 26 April-4 May 1993 (sector III)

Area

$\begin{array}{cc}\text { Ai. undeformed } & \% \text { ice area } \\ \text { ice thickness } & \text { ridged }\end{array}$
ridged

Av. ice lhickness
with ridging

Av. deformed! av. undeformed

m

m

Sector $I$

Total

0.37

13

$050 \mathrm{~km}$

0.11

$50-150 \mathrm{~km}$

0.12

$150-350 \mathrm{~km}$

0.24

$350-550 \mathrm{~km}$

0.49

0.43

0

0.11

0.12

0.39

0.95

$>5.50 \mathrm{~km}$

14

1.64

Sector $I I I$

Total

50-150 km 
seasonal variations in the cover of different thickness categories, as well as the variation in ice thickness with distance from the ice edge, have been identified in the area $60^{\circ}-150^{\circ} \mathrm{E}$.

The area-averaged ice thickness has been calculated for the undeformed component of the pack, which compriscs $70-80 \%$ of the total area in each sector. This undeformed area-averaged thickness is typically about $0.5 \mathrm{~m}$, and heat loss through thin ice and open water may account for more than $80 \%$ of the total heat exchange between the ocean and atmosphere (Worby and Allison, 1991). However, to account for the mass of ice in pressure ridges, the undeformed area-averaged ice thickness in spring must be increased by betwecn 1 and 4 times, to give a total average thickness (depending on region) of between 1 and $2 \mathrm{~m}$. The considerable ice mass in ridges is important for determining the total mass budget of the pack ice, but it has little effect on the total energy budget of the sea-ice zone, because of the non-linear relationship between the turbulent heat fluxes and ice thickness discussed by Worby and Allison (1991).

In the late spring when the sea ice is at its maximum extent, the mix of ice-thickness categories is greatest. New ice forming in leads and areas of extensive ridging are present in most zones of the pack. 'The outer $350 \mathrm{~km}$ of the pack, in the Antarctic Circumpolar Current, is a zone of relatively uniform ice characteristics between sectors, whilst further south, local coastal and bathymetric features cause significant variability in ice drift and hence in the thickness distribution. There is evidence of this in sector III, where pressure ridges up to $10 \mathrm{~m}$ thick can be found in all zones. This contrasts with sectors $I$ and $I I$, where ridges average $1-4 \mathrm{~m}$ thick and are confined mainly to the zones $>150 \mathrm{~km}$ south of the ice edge. As a consequence, the area-averaged ice thickness in spring, including ridging, is only $1 \mathrm{~m}$ in sector I but $2 \mathrm{~m}$ in sector III.

The proportion of thin ice within the pack decreases through October and November, and by December only ice $>0.3 \mathrm{~m}$ thick remains. With the exception of sector
III, little ice survives the summer melt and by FebruaryMarch the new growth season starts over again.

\section{ACKNOWLEDGEMENTS}

The authors are grateful to the officers and crew of RSV Aurora Australis and MV Icebird for their assistance in deployment and recovery of personnel and equipment to ice floes, and to passengers who have helped with the field sampling. Passengers and crew have also assisted with icecharacteristics observations on some voyages.

\section{REFERENCES}

Allison, I. 1989a. The East Antarctic sea-ice zone: icc characteristics and drift. Geojournal, 18(1), 103-115.

Allison, I. 1989b. Pack-ice drift off East Antarctica and some implications. Ann. Glaciol, 12, 1-8.

Allison, I., R. E. Brandt and S. G. Warren. 1993. East Antarctic sea ice: albedo, thickness distribution and snow cover. 7. Geophys. Res., 98(C7), 12,417-12,429.

Lange, M., A. P. Schlosscr, S.F. Ackley, P. Wadhams and G.S. Dicckmann. $1990 .{ }^{18} \mathrm{O}$ concentrations in sea ice of the Weddell Sea, Antarctica. 7. Glaciol, 36(124), 315-323.

Maykut, G. A. 1978. Energy exchange over young sea icc in the central Arctic. J. Geophys. Res., 87(C10), 3646-3658.

U.S. Naval Oceanography Command. 1985. Sea ice climatic atlas. Volume 1 Antartica. Navair 50-1c-540. Asheville, U.S. Naval Occanography Gommand.

Wadhams, P., M. A. Lange and S.F. Ackley. 1987. The ice thickness distribution across the Atlantic sector of the Antarctic Occan in midwinter. 7. Geophys. Res., 92(C13), 14,535-14,552.

Worby, A. P. and 1. Allison. 1991. Ocean-atmosphere energy exchange over thin, variable concentration Antarctic pack ice. Ann. Glaciol., 15, $184-190$.

World Metcorological Organization. 1970. WMO sea-ice nomenclature, terminolugy, codes and illustrated glossary. WMO/OMM/BMO 259, TP 145. Geneva, World Meteorological Organization.

The accuracy of references in the text and in this list is the responsibility of the authors, to whom queries should be addressed. 